\title{
Mobile Networks: \\ Visualizing the Global Refugee Regime
}

\begin{abstract}
This article identifies conceptual issues surrounding the visualization of refugee movement in relation to state borders. It argues that social-network-analysis software provides a tool for the creation of visualizations of human movement that are removed from geolocation. Such a method disassociates forced migration from preconceived notions about the importance of geographical proximity and the fixity of state borders. This article provides some brief examples of ways that these methods might be utilized to graph and visualize aspects of the global refugee regime. The global-scale, transnational conceptualization and new visualizations show networks of movement centered on new inter-state communities and highlights the role of non-state actors.
\end{abstract}

Volume 2-3, No. 1 (2014-2015) | ISSN 2169-0812 (online)

DOI 10.5195/jwhi.2015.11 | http://jwhi.pitt.edu 


\section{Bennett Gabriel Sherry}

\section{Mobile Networks: Visualizing the Global Refugee Regime}

Refugee crises are fundamentally transnational phenomena; however, refugee migration is too often portrayed as an international process. Analysis of refugee migration should focus on the intersections between the transnational life of refugees and the international character of state foreign relations. ${ }^{1}$ States and interstate relations are crucial to the processes of refugee movement; they protect refugees, they resettle refugees, and conflicts within or between states cause refugee displacement. But in this analysis of international policy and its impacts on refugee migration, we must not lose sight of the transnational character of these migrants - the ways in which they defy and transcend state borders and categories. Refugees are defined and categorized based on their relation to nation states, to their impact on foreign and domestic policy; however, a refugee is, by definition, one who has crossed a state border and who is unable or unwilling to seek protection from their state of nationality. ${ }^{2}$ Treating refugee migration solely as a function of international relations lacks an appreciation for the complex nature of refugee movement and the networks and institutions that facilitate it. ${ }^{3}$ In the data gathered by the United Nations, refugees are categorized according to a limited set of criteria - state of origin, state of asylum, state of resettlement, and status recognition which defines refugees by their relation to states. ${ }^{4}$

Humans become refugees when the international system is unable to respond through traditional channels of state sovereignty to conditions that displace populations. In the sixty five years since the 1951 Convention relating to the Status of Refugees, forced migration has increased, and the central structures of state response have been slow to adapt. States are central factors in the refugee experience, but finding new ways to map refugee space is necessary to comprehend the trans- and extra-national character of refugee migration and of the global refugee regime itself. Emerging data visualization tools are providing new methods for humanists to engage with refugee issues. Geographic Information Systems (GIS) software provides an extraordinarily useful set of tools; however, it is the contention of this paper that, to extricate refugee migration from state-dominated analyses, social network analysis provides an important alternative for refugee data visualization that is less dependent on geo-location and thus, less referential to state borders and state control.

The refugee regime is here defined as the coalescence of interstate, state, non-state, group, and individual actors and their attendant institutions around a given refugee crisis or set of crises. The global refugee regime is a migration system composed of the constellations formed at a planetary level by these various coalescences around refugee crises. ${ }^{5}$ This paper explores the implications of the digital visualization of data for mapping the complex 
relationships and interactions of refugee migration. Focusing on the transnational characteristics of migration data allows us to rethink refugee movement in a way that downplays the significance of national borders and subtly shifts the narrative from the state towards the migrants. ${ }^{6}$ Social network analysis software enables representations of space based on refugee migration data that affords opportunities to challenge state-based geographies. ${ }^{7}$

Several projects that visualize global refugee flows have emerged in recent years. ${ }^{8}$ These projects are excellent representations that provide a great deal of analytical and descriptive value in a global climate where forced migration is a reality that touches the lives of millions of people. These visualizations are useful; however, all share one thing in common: they are map based, and they represent refugee movement as a series of straight lines from state to state. These characteristics emphasize the prominence of the state, reinforce the notion that migration is referential to state borders, and they minimize the complexity of refugee movement. In visualizations created almost entirely with data that is created by interstate organizations for state-level analysis, these characteristics are perhaps unavoidable. Moreover, accurately representing the complexity of refugee movement is prohibitively labor intensive on a macro scale. We should, however, augment the existing methods of visualization with methods that minimize the fixity of geographical proximity and political boundaries.

This is not to argue that visualizations that rely on state-based geographies are bad. Indeed, they are often the only coherent way to convey visualizations of refugee movement in a manner that retains meaning for lay audiences. My argument here is merely that alternative visualizations provide a means to supplement geographic and statebased visualizations in order to locate unexpected interactions and to maximize the visibility of the roles played by non-state actors in visualizations.

Removing visualizations of the refugee regime from geographical maps - of color-coded countries and continents superimposed across representations of geo-locational space to denote state borders - and placing them within a relational graph of edges and nodes causes several things to happen. Of course, much is lost in this transfer. Important contextual aspects of geographic space are certainly lost. Maps are useful; however, by losing the map, we also lose the preconceptions tied to maps. Divisions between East and West, Europe and Asia - these things fade to the background as the tool allows a focus on the connections and interactions among the entities represented by the data. By removing the map we remove the mental distortions caused by state borders and the arbitrary factors of proximate location. Relational graph representations of refugee space should not replace geographical representations, but these graphs allow visualizations that emphasize aspects of data that would otherwise be obfuscated by geography, and they enable a visualization of refugee migration that minimizes the role of states. Graphical visualizations are perhaps one possible answer to the criticism that migration history is overly dependent on state-based data. ${ }^{9}$

The graphs in Figures 1-12, which I produced using Gephi, a software platform for the visualization and exploration of networks and complex systems, link states to each other based on a relational connection. I chose to use alliance data (Figures 1-6) and forced migration data (Figure 7-12) here, though similar graphs utilizing data of conflict, trade, refugee regime interaction, and a variety of other binary relationships are possibilities as well. In each of the attached graphs I have scaled the size of the circular nodes of states in proportion to the amount of refugees residing in that country during that year. ${ }^{10}$ These graphs are not complete or perfect, but they begin to suggest methods for representing refugee space in complex ways that might help reveal connections that are elided by maps based on geo-location. 
In constructing the graphs in Figures 1-6, I utilized three datasets: the dyad-year alliance dataset from Rice University's Alliance Treaty Obligations and Provisions Project (ATOP), refugee country of residence data from the UNHCR's statistical database, and the Correlates of War Country Code dataset. The country code and refugee data combined to form my unique nodes and their size reflects the population of refugees in that country. The ATOP alliance data formed my edges. The dyad-year dataset has a single instance for every year that two states were allied with one another. The set designates five types of alliances by level of obligation: defensive, offensive, neutrality, nonaggression, and consultation. ${ }^{11}$ I coded a weight from 1 to 10 for each of the five types of alliances included in the dataset and added this number in a sixth column to provide an overall weight for each alliance edge between two states. To standardize the node territory-name information obtained from the UNHCR database with the state-name column of the ATOP dataset, I utilized the Correlates of War Country Code identifiers, which are also used by ATOP. I used Google Fusion Tables to combine my UNHCR node data with the Correlates of War country code table, which required me to reconcile the naming differences between the two sources. This decision-making process was not simply one of nomenclature - the UNHCR data includes Palestinians, Tibetans, and French Guyana as separate entities, while the Correlates of War does not recognize these groups as states. In the case of French Guyana and European possessions in the Caribbean, I included the groups as discreet entities in my refugee flows graph but not in the state alliance graph, as they lacked alliance edges. In the graphs based on refugee flows (Figures 7-12), I accepted the UNHCR’s decision to treat them as discreet territories of refugee migration.

The data used to produce Figures 7-12 included the same sources for nodes, but the edges were based on directed forced migration flows from country of origin to country of residence, which I pulled from the UNHCR's statistical database. This dataset distinguishes between "Internally Displaced Persons (IDPs)," "refugees," "asylum seekers," "returned IDPs," "returned refugees," "stateless persons," and "others of concern.” The edge weights for these graphs are determined by the amount of that particular group in that particular movement from state to state. In figures 9-12 I created each refugee group as its own discreet node, each with two weighted edges, one from the state of origin and one to their state of residence. In figures 7-8, refugees are present as the edges between states, and their weight determines the organization of the graph. In figures 9-12, refugees are present both as their own individual nodes and in the weighted edges, which represent their movement between territories. As discussed below, even this small step away from a state-centered graph has a significant impact on a visualization of the global refugee regime.

Social network analysis can be a productive tool in exploring refugee issues in one very particular way: it allows for a reconceptualization of the transnational aspects of refugee movement in the context of international relations. If my goal is to transcend states in a visual representation of refugee space, and my data are collected by and in reference to state and interstate agencies, then I am required to find a manner of representing refugees within a state-based relationship, but one which minimizes the state as the important actor in the visualization. Gephi's software allowed me to take the first steps toward this. By tying the size of the nodes to the amount of refugees resettled I am able, in a small way, to place emphasis on the refugees as central factor in the organization of the global refugee regime. The refugee numbers in these visualizations are still based on and informed by their relation to particular states; however, by removing them from geographical contexts, the emphasis is placed on other aspects. Relative centrality of connection determines the location of the node on the graph, and the population size of the refugee groups themselves determines the relative magnitude of each node. States that might otherwise carry an outsized weight in any regional or global analysis are reduced in significance if they share few interactions with other actors or if they do not interact with refugees as specified by the parameters of the graph.

In figures 1-5 below, state relationships to other states determine their relative centrality to the graph, but it is the size of certain nodes that draws the eye. Russia, (Figure 5) though centrally located, nevertheless appears less 
significant due to the relative size of its node. Pakistan's weight in the visualization, despite the state's lack of alliance centrality, is emphasized as a result of the refugees living within its borders. If we remove the edges all together (Figure 6) - leaving only the nodes proportioned according to refugee population but still grouped based on the closeness of the alliance systems - this effect is multiplied.

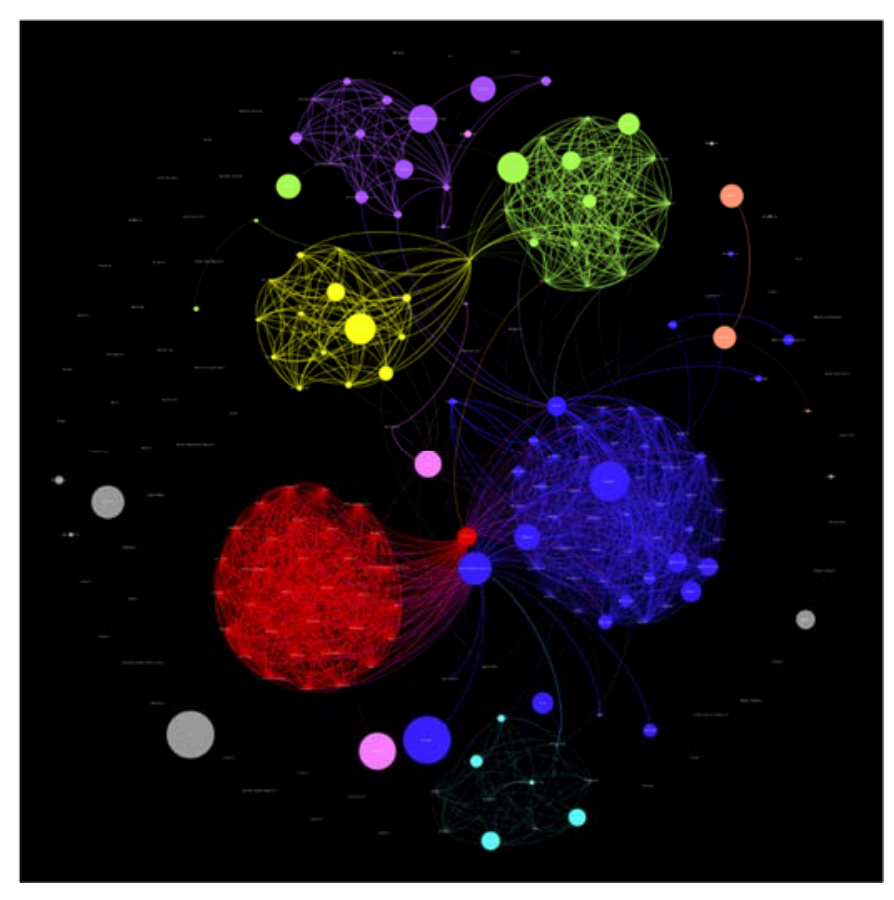

Figure 1 (1999) 


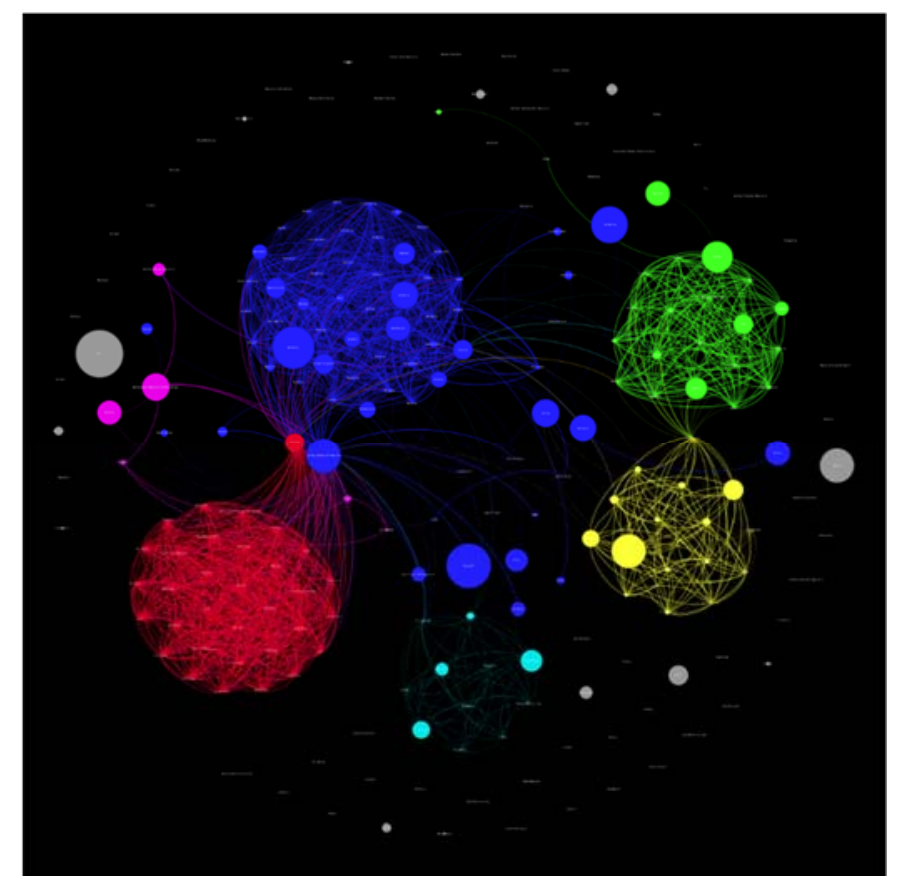

Figure 2 (2000)

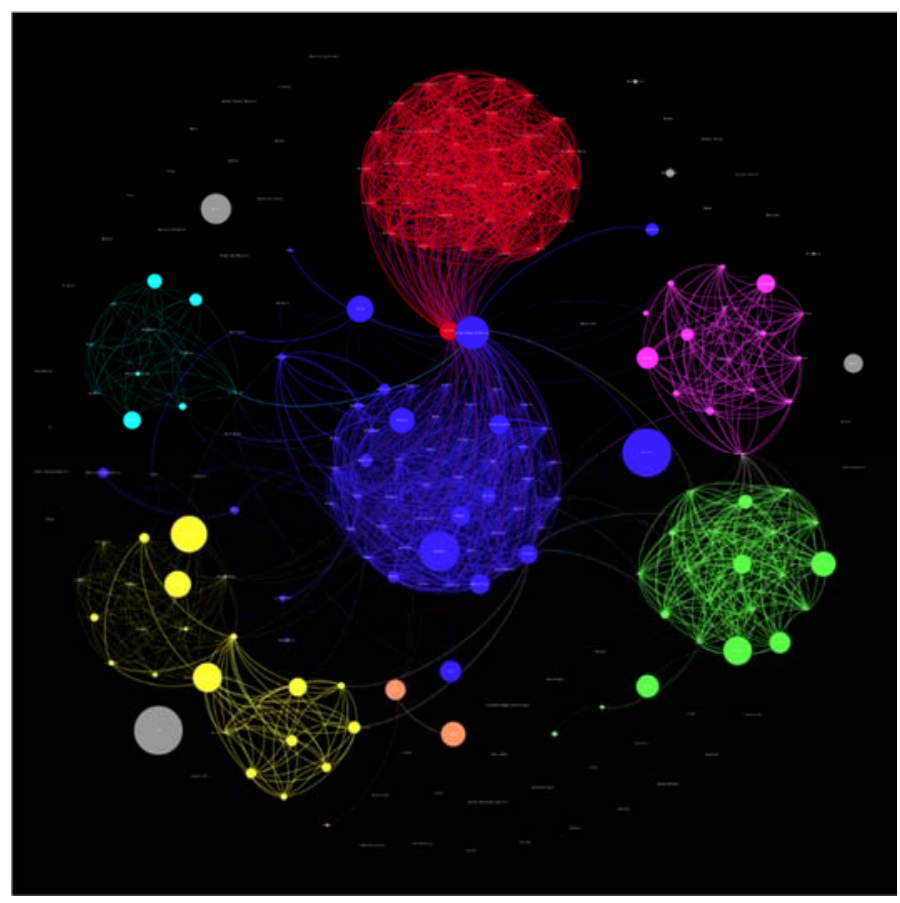

Figure 3 (2001) 


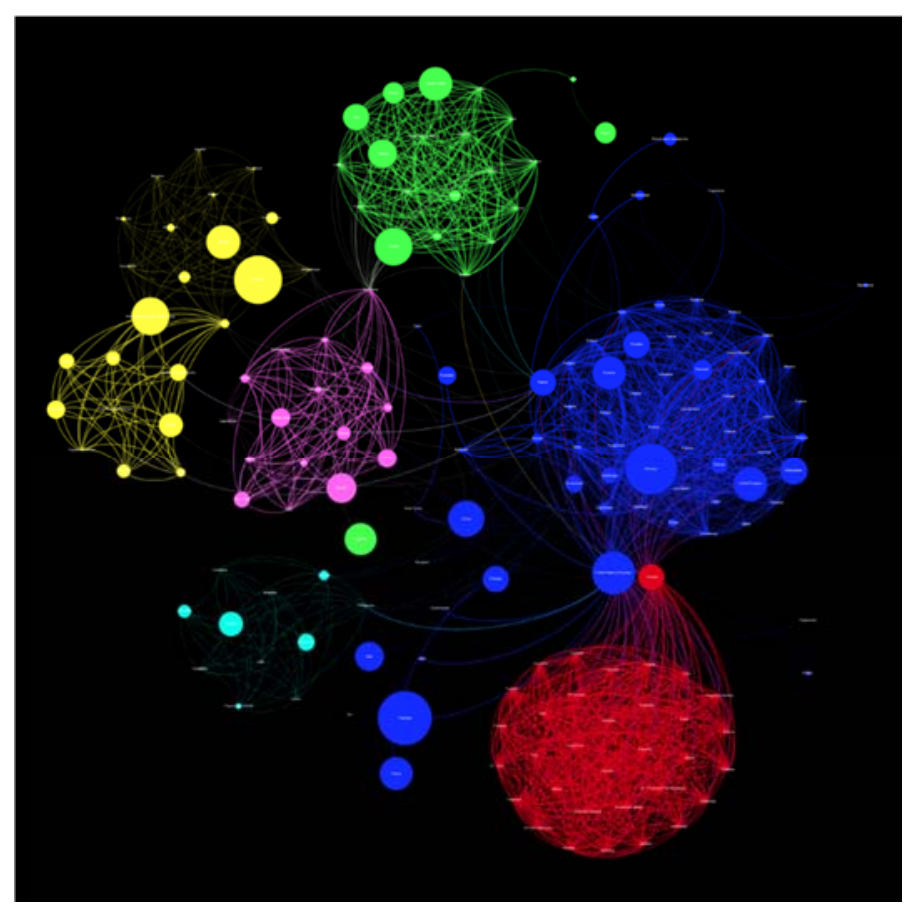

Figure 4 (2002)

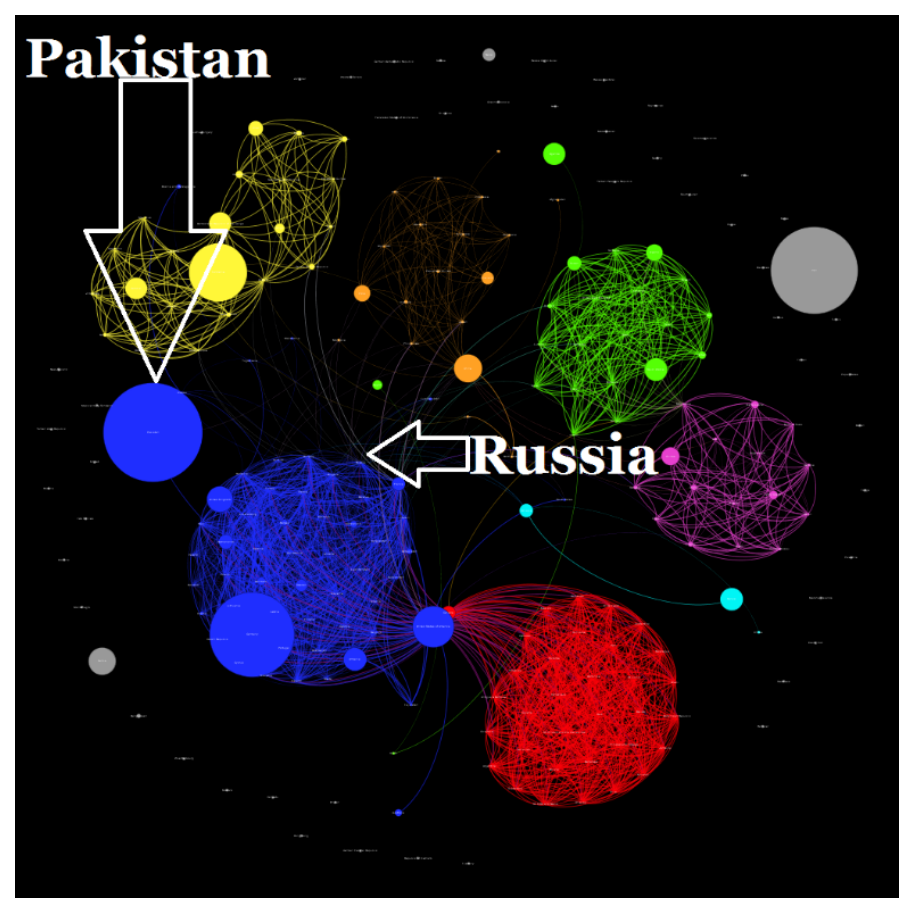

Figure 5 (2003) 


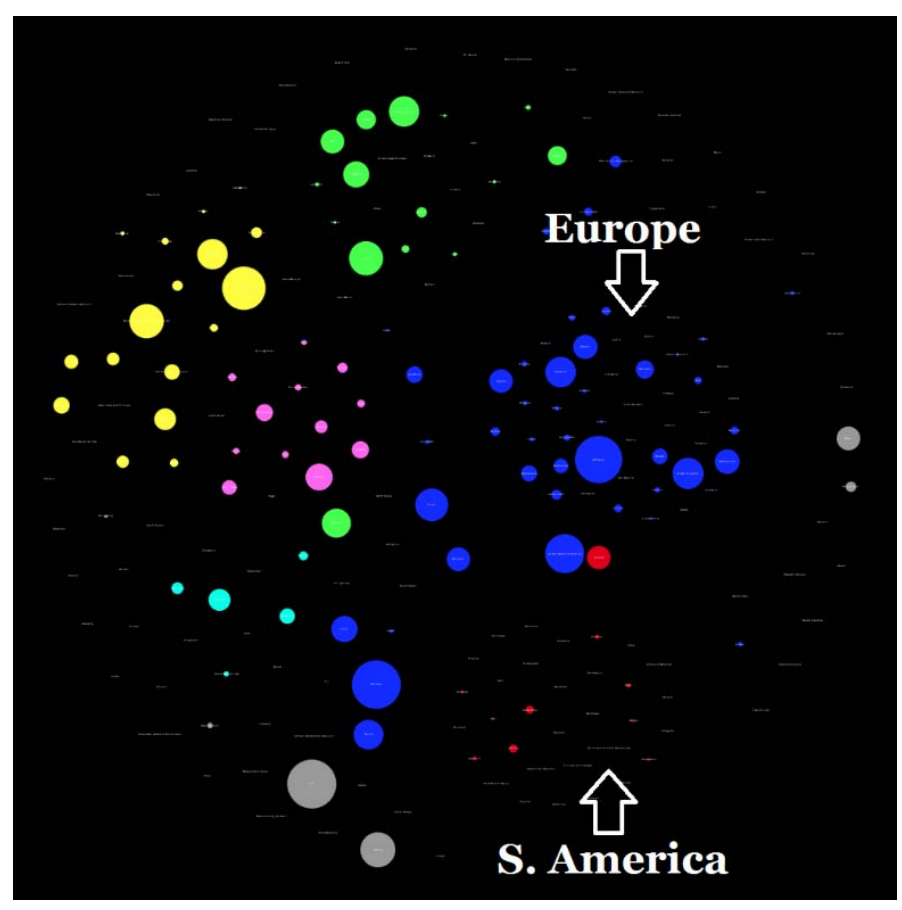

Figure 6 (2002)

Representations of the refugee regime as a social network raises the important question of scale. It is my contention that the visualization power of relational graphs to provide meaningful representations of the refugee regime is strongest at the regional level, while the analytical power of these graphs is most prominent at a global level of analysis. Utilizing data at the regional level incorporates some aspects of geo-locational bias; however, it also allows for the graph to be built "out" from a particular refugee crisis. This would permit the construction of a graph to visualize the coalescence of the international refugee regime around a particular crisis such as that caused by the present conflict in Syria. By starting at a regional level, the creator of this graph may work outward from a particular crisis, drawing connections based on involvement in the conflict - where refugees go, who cares for them, how they are protected under international law.

A global scale of analysis, on the other hand, provides a different analysis of the configuration of refugee regime. At this scale, the focus of the visualization is not on the coalescence of actors around a specific crisis but on how the constellations of these coalescences interact on a planetary level. The primary advantage of this scale is that it enables the identification of networks of exchange and interaction that can replace geographic designations. In Figure 7, several distinct groups with prominent populations of refugees emerge. The pink cluster centrally located in the graph is centered on the movement of refugees among Iran, Pakistan, and Afghanistan. This type of community selection enables a further step away from arbitrary regional and geographic distinctions. Communities are selected, not necessarily for their geographical proximity, but based on their level of shared interactions. The data visualization tools provided by Gephi affords a powerful suite of tools to reveal these sorts of connections and interactions. 


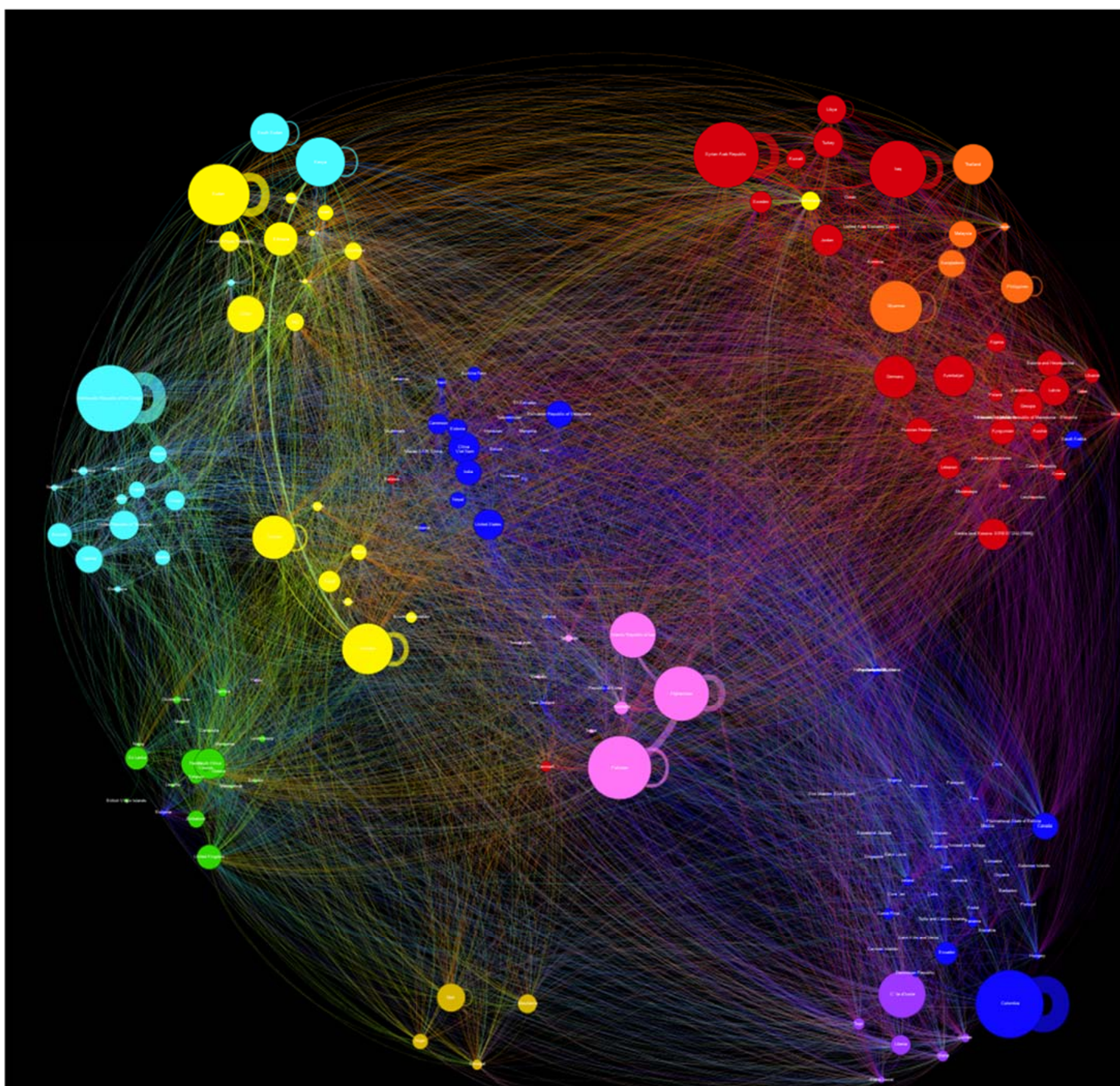

Figure 7 (2012) 


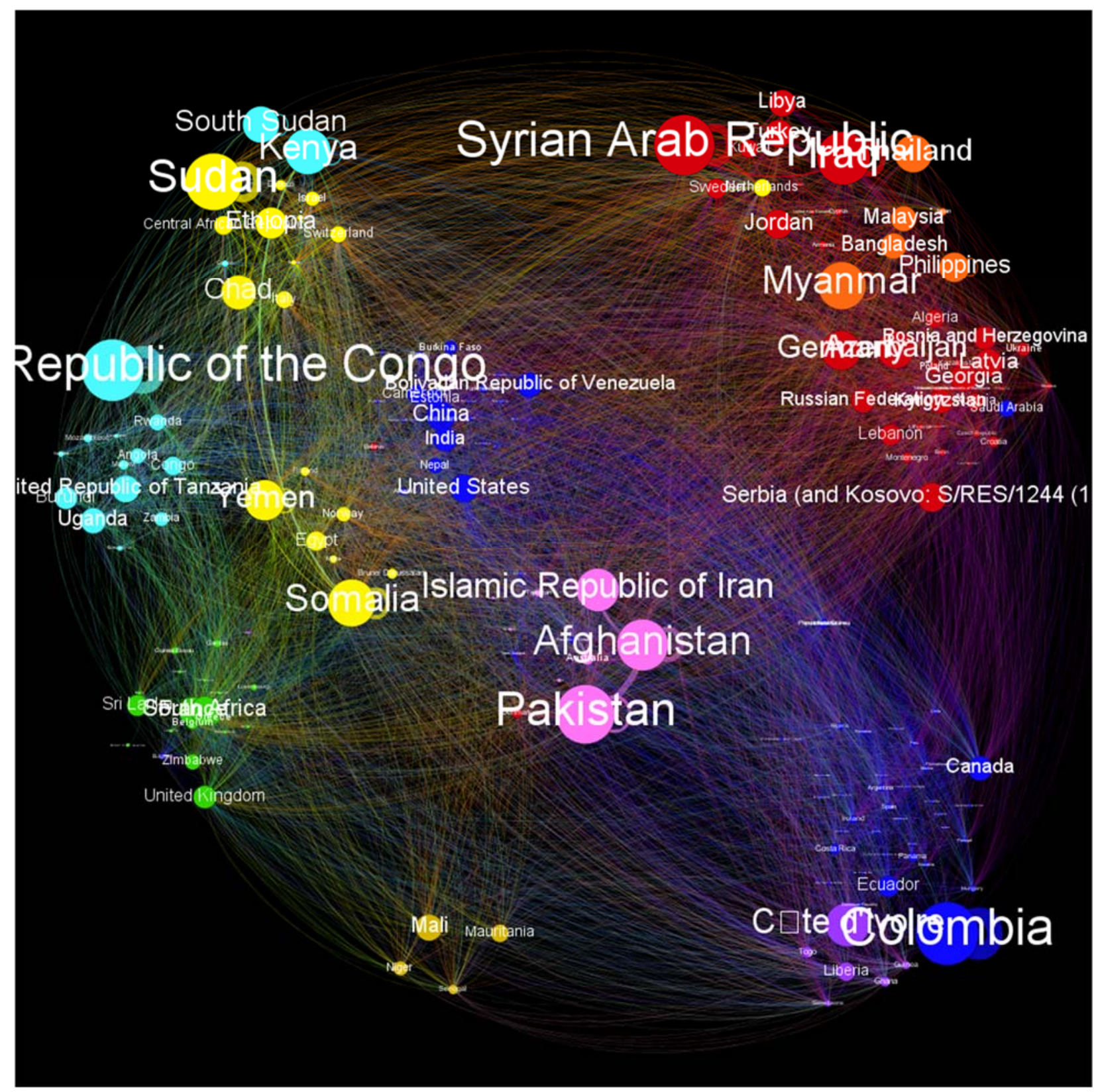

Figure 8 (2012)

The graphs in figures 7 and 8 suggest several groupings of states based on their shared exchanges of refugee migrations. Producing refugee groups (i.e. "refugees from Afghanistan to Pakistan” or "IDPs from Columbia to Columbia" or "asylum seekers from Turkey to Germany") as their own discreet nodes, connected to the interstate refugee migratory system by edges based on their own movement, the graph becomes much more complex (Figures 9-12). Relational clusters are now based around particular refugee crises. The modularity of the graph - the 
statistical process through which nodes are grouped together based on shared edges - can be altered to include more communities or to simplify the graph into only a handful of distinct communities (Figure 11).

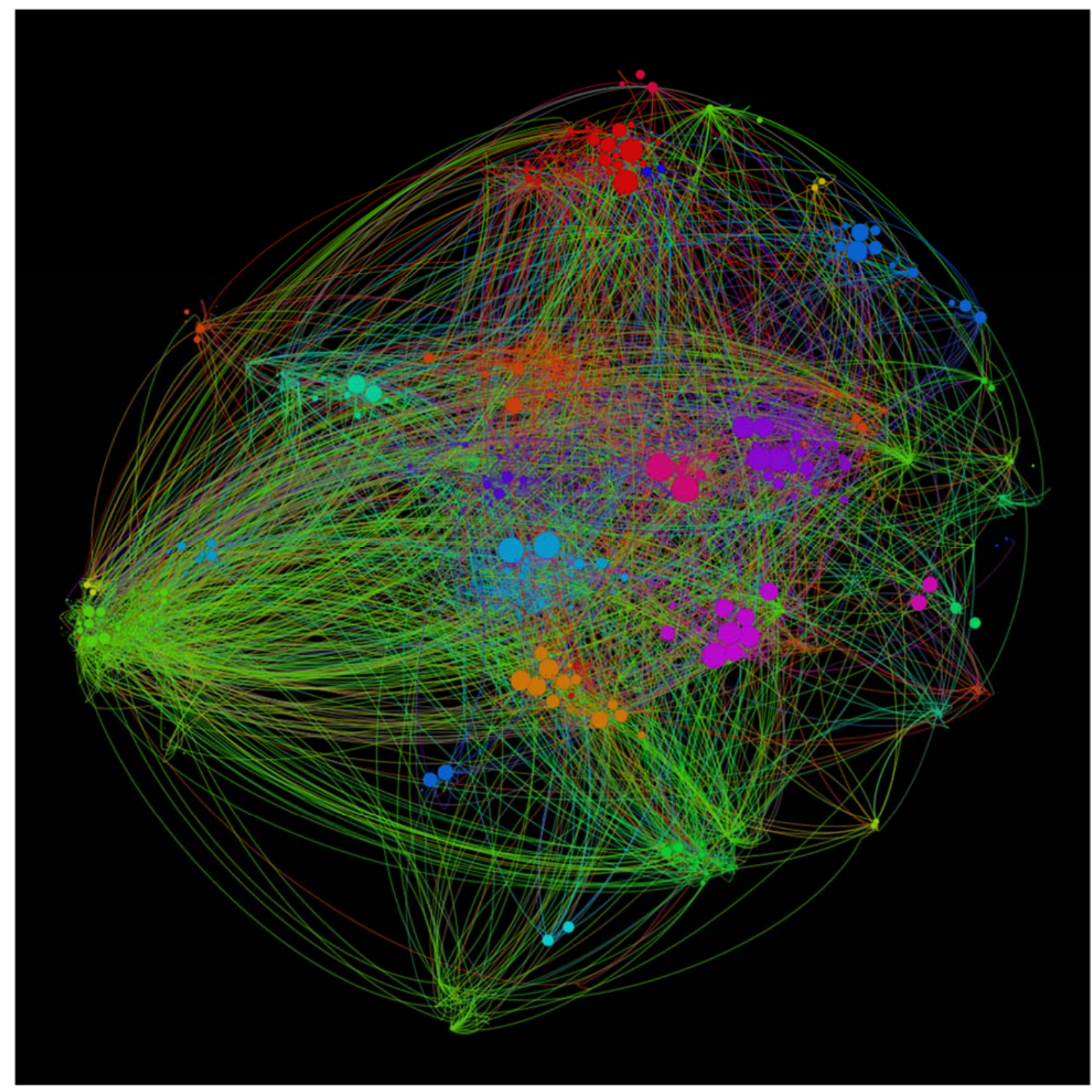

Figure 9 (2012) 


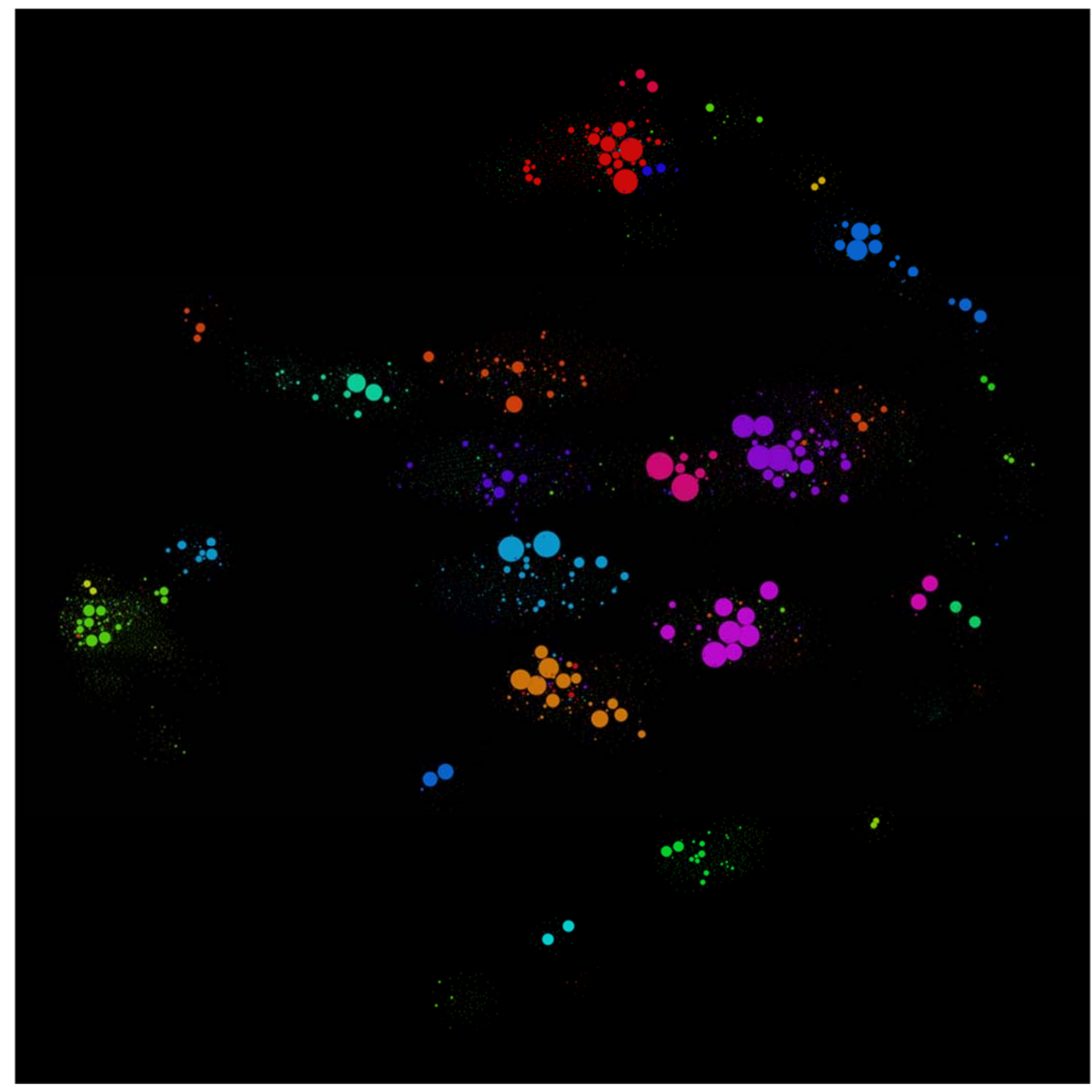

Figure 10 (2012) 


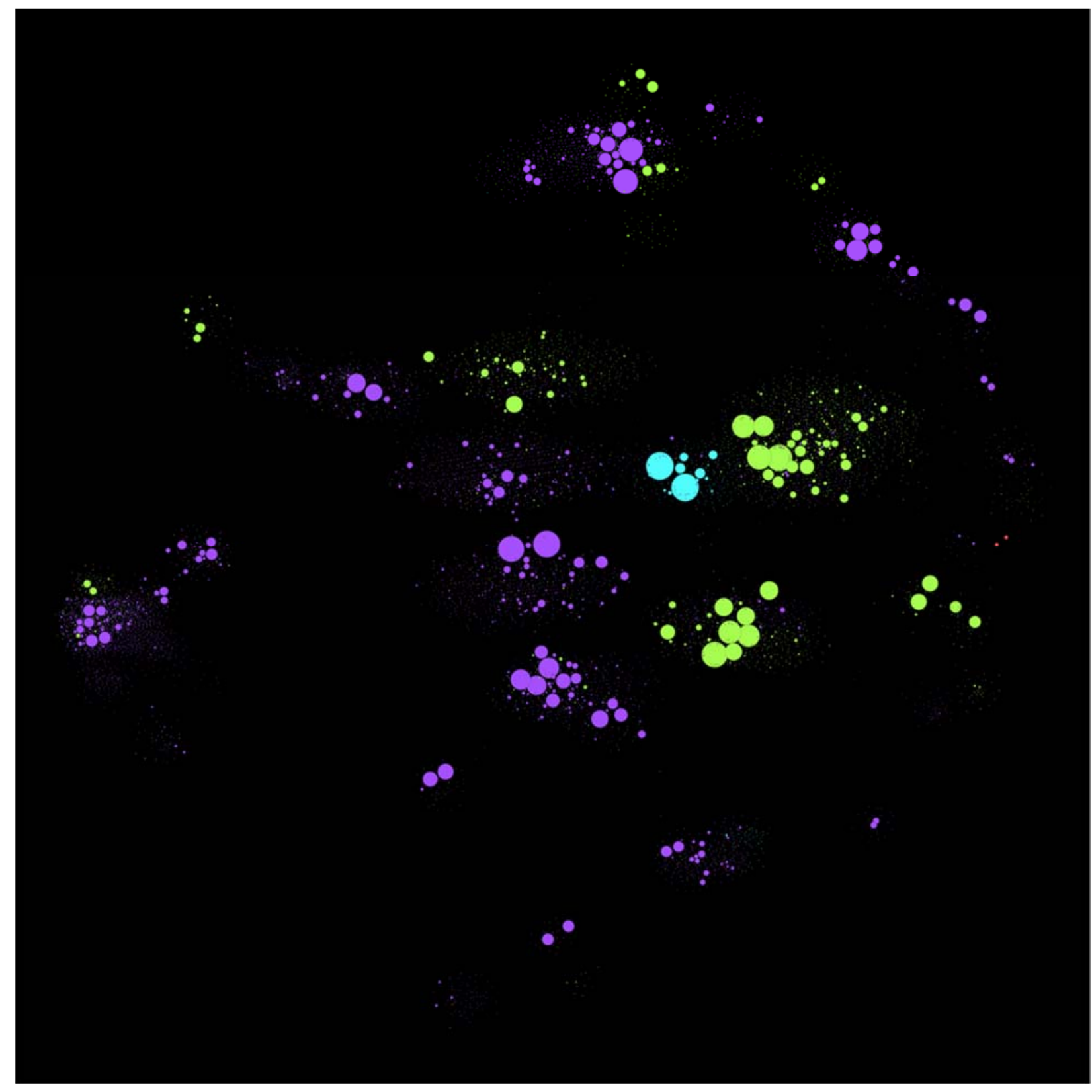

Figure 11 (2012) 


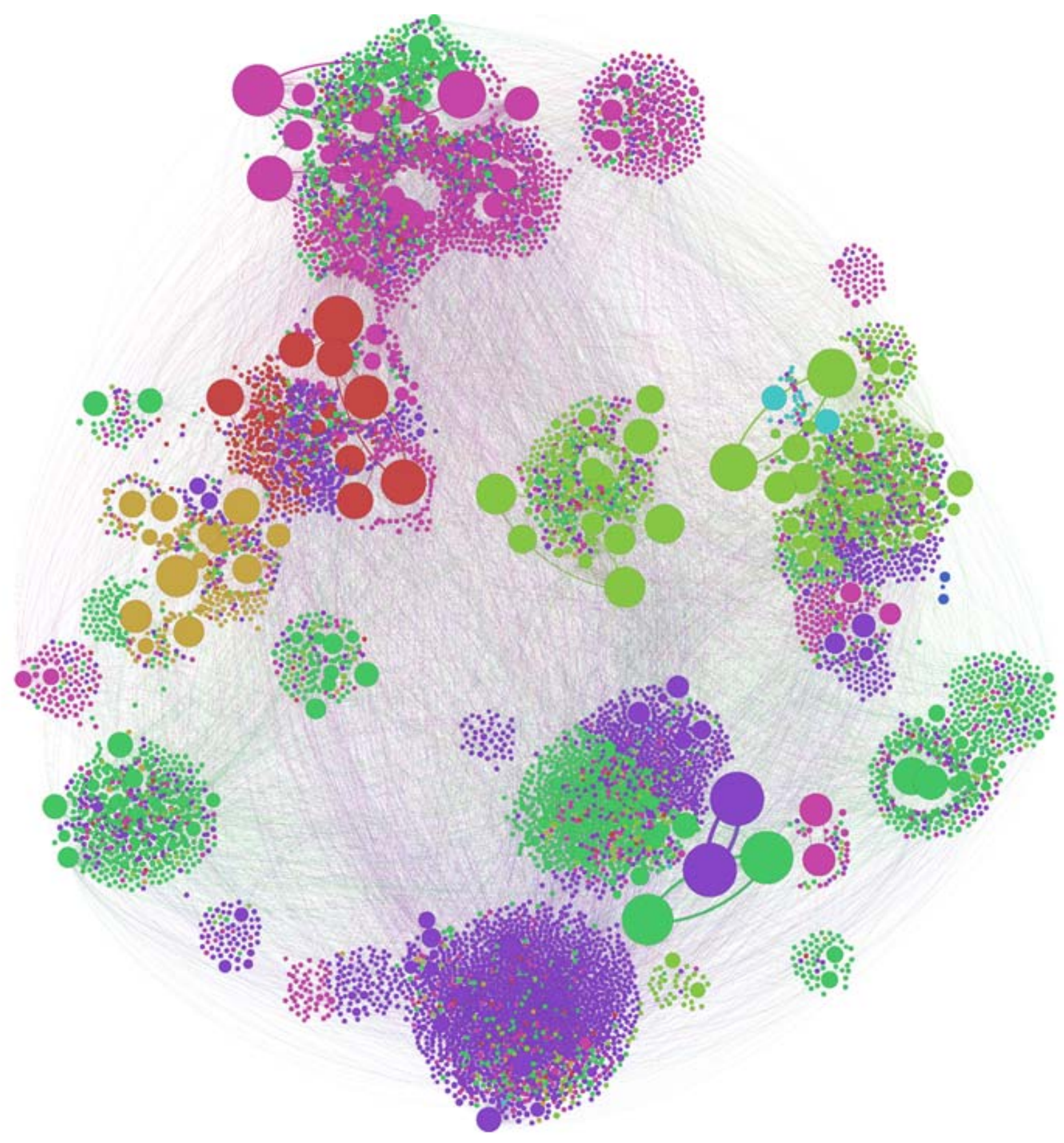

Figure $12(2012$

A more complete visualization of the regime that facilitates refugee migration requires the inclusion as nodes more actors beyond states. The refugee regime is a constellation of actors converging around a particular refugee crisis; it is defined by a collection of interests, international laws, and actors devoted to addressing the problem of refugees. Moreover, many of these actors, especially organizations like the United Nations, the Red Cross, and Caritas are not as explicitly tied to a single geography as are states. They might be headquartered in a particular city, 
but they are transnational as well as international actors, and they operate at several scales of analysis. Social network analysis might be utilized for more complex visualizations of the multifaceted nature of the refugee regime. Refugee groups, individuals, NGOs, IGOs, and states could be included as equal data points and represented as nodes, with edges as degrees of connection based on the actor's involvement with a particular refugee group. The obstacles to this project are primarily the collection and interpretation of data, so much of which is based on a subjective decision of who is internal and who is external to a given refugee crisis.

This project has highlighted several possible benefits provided by a resource like the Collaborative for Historical Information and Analysis (CHIA) database. First is its ability to receive and host data from diverse sources, standardized for specific usage. In constructing these graphs I was required to reconcile metadata distinctions between four separate datasets. Each source labeled countries differently, had a different selection of countries, and even differed on what countries should be included as independent entities. Going forward, my use of refugee data would benefit from a combination with larger migration datasets provided by the World Bank and United Nations to enable a comparative analysis between refugee-specific and global migration data. CHIA would afford me a repository for my standardized data as well as an opportunity for others to utilize or add to it. A genuine visualization of the refugee regime over time will require labor intensive collection of data from textual sources, as the UNHCR's digital data collection extends only to 1965, and is limited before 1999.

\section{NOTES}

${ }^{1}$ Donna Gabaccia, Foreign Relations: American immigration in Global Perspective (Princeton: 2012), x, 4. For a discussion of the transnational characteristics of migrants, see: Linda Basch, Nina Glick Schiller, and Cristina Szanton Blanc, Nations Unbound: Transnational Projects, Postcolonial Predicaments, and Deterritorialized Nation States (Basel: 1994)

${ }^{2}$ Gil Loescher and Andrew Scanlan, Calculated Kindness: Refugees and America's Half-Open Door, 1945Present (New York: The Free Press, 1986), 41, 84. Carl Bon Tempo, Americans at the Gate: The United States and Refugees During the Cold War (Princeton: Princeton University Press, 2008), 173. The 1951 Convention Relating to the Status of Refugees (amended by 1967 Protocol) defines a refugee as: "A person who owing to a well-founded fear of being persecuted for reasons of race, religion, nationality, membership of a particular social group or political opinion, is outside the country of his nationality and is unable or, owing to such fear, is unwilling to avail himself of the protection of that country..." Convention and Protocol Relating to the Status of Refugees, UNHCR, http://www.unhcr.org/3b66c2aa10.html

${ }^{3}$ Douglass Massey, Joaquín Arango, Graeme Hugo, Ali Kouaouci, Adela Pellegrino, and J. Edward Taylor, “Theories of International Migration: A Review and Appraisal," Population and Development Review 19: 448-451.

${ }^{4}$ Refugees are categorized by the UNHCR based on their asylum status: refugee, internally displaced persons (IDP), asylum seekers, stateless persons, returned IDPs, returned refugees, and others of concern. "UNHCR Statistical Online Population Database," United Nations High Commissioner for Refugees (UNHCR), date accessed: 02/15/2015. www.unhcr.org/statistics/populationdatabase

${ }^{5}$ For a summary of migration systems theory see, Thomas Faist, “The Crucial Meso-Level," in Thomas Hammar, Grete Brochmann, Kristof Tamas, and Thomas Faist, eds. International Migration, Immobility and Development: Multidisciplinary Perspectives (New York: Bloomsbury Academic, 1997); and Patrick Manning and Tiffany Trimmer, “Appendix: Migration Theory and Debates," in Patrick Manning, Migration in World History $2^{\text {nd }}$ ed. (New York: Routledge, 2013), 191-205. 
${ }^{6}$ Basch et. al., Nations Unbound, 3-5, 22-25.

${ }^{7}$ Leeds, Brett Ashley, Jeffrey M. Ritter, Sara McLaughlin Mitchell, and Andrew G. Long. 2002. Alliance Treaty Obligations and Provisions, 1815-1944. International Interactions 28: 237-260. http://atop.rice.edu/data; “Table with Data on Refugees,” in UNdata: A World of Information, accessed 02/15/2015. http://data.un.org/Data.aspx?d=UNHCR\&f=indID\%3aType-Ref; Correlates of War Project. "COW Country Codes," Accessed 02/15/2015. http://correlatesofwar.org; "UNHCR Statistical Online Population Database," United Nations High Commissioner for Refugees (UNHCR), data extracted: 02/15/2015. www.unhcr.org/statistics/populationdatabase;

8 Prominent examples include: http://www.therefugeeproject.org/\# ; http://data.unhcr.org/dataviz/ ; http://www.niceone.org/lab/refugees/

${ }^{9}$ Lucassen and Lucassen identify state-based data as one of the greatest limits in migration history. Jan Lucassen and Leo Lucassen, "From Mobility Transition to Comparative Global Migration History," The Journal of Global History 6 (2), 305-306.

${ }^{10}$ This attribute visualization could be accomplished using any integer value. For instance, country of origin could be used in place of country of residence.

${ }^{11}$ ATOP’s codebook can be downloaded from their website: http://atop.rice.edu/download/ATOPcdbk.pdf

States License.

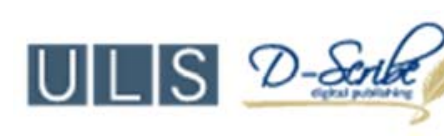

This journal is published by the University Library System of the University of Pittsburgh as part of its D-Scribe Digital Publishing Program and is cosponsored by the University of Pittsburgh Press. 